\title{
Aqueous Enzymatic Extraction of safflower (Carthamus tinctorius L.) seed oil: A preliminary study
}

\author{
Chaymae Benkirane ${ }^{* 1}$, Aymane Allay ${ }^{1}$, Abdessamad Ben Moumen ${ }^{1}$, Kamal Belhaj ${ }^{2}$, Reda \\ Melhaoui ${ }^{1}$, Farid Mansouri ${ }^{1}$, Malika Abid ${ }^{1}$, Hana Serghini-Caid ${ }^{1}$, and Ahmed Elamrani ${ }^{1}$ \\ ${ }^{1}$ Laboratory of Agricultural Productions Improvement, Biotechnology and Environment (LAPABE), \\ Faculty of Sciences, Mohammed I University, Oujda, Morocco. \\ ${ }^{2}$ Laboratory of Sustainable Agriculture Management, Higher School of Technology, Sidi Bennour, \\ University Chouaib Doukkali, El Jadida, Morocco.
}

\begin{abstract}
Reducing the pollution is a serious environmental challenge facing the oil producing industry worldwide. Conventionally, oil from oleaginous is extracted in large scale by mechanical expression or organic solvent extraction. In spite of its high yield, organic solvent extraction is time-consuming and very harmful to health and environment. Aqueous Enzymatic Extraction (AEE) is an eco-friendly extraction method using water as an extraction medium. Its application is a feasible alternative to traditional processing technologies without using organic solvents. However, its efficiency depends on many factors. This study aims to investigate the potential of AEE method to extract oil from safflower (Carthamus tinctorius L.) seeds using hemicellulase. Four extraction parameters with different levels that are incubation temperature, incubation time, initial $\mathrm{pH}$, and enzyme concentration were evaluated. The optimum extraction conditions recorded were $65^{\circ} \mathrm{C}, \mathrm{pH} 5,4 \% \mathrm{w} / \mathrm{w}$ of enzyme and 3 hours of incubation. The obtained results showed that AEE reach a maximum of $70.45 \%$ oil recovery. Therefore, Aqueous Enzymatic Extraction can be suggested as an environmentally cleaner alternative method to efficiently extract oil from safflower seeds.
\end{abstract}

\section{Introduction}

Safflower (Carthamus tinctorius L.), also called false saffron, is an herbaceous plant belonging to the Asteraceae family. It has been cultivated since antiquity for its ornamental and dyeing properties in several regions of the world notably in Indian and Egyptian civilizations [1]. Nowadays, it is mostly grown for its oilseeds containing $26-48 \% \mathrm{w} / \mathrm{w}$ of oil $[2,3]$ depending on plant genotypes, environmental cultivation conditions and extraction methods.

Safflower seed oil has a yellowish color and a slightly nutty flavor [4]. It is considered as a versatile product since it is known for its culinary, medical, cosmetic, and technical

* Corresponding author: chaymae.1.benkirane@gmail.com 
uses. Indeed, safflower oil is very rich in unsaturated fatty acids especially linoleic acid (approximately 80\%) [5], which make it excellent for human consumption. It is also used in traditional medicine owing to its hypocholesterolemic, anti-diabetic, cardioprotective, antioxidant, and anti-inflammatory virtues. In addition, safflower oil fluidity and lightness properties make it ideal for cosmetic uses such as skin hydration and hair care. It also appears in the formulation of several dermatological and care body products. Moreover, there is other industrial and technical applications of safflower oil such as varnish and biodiesel production $[1,4,6]$.

Several extraction methods are used conventionally for safflower oil extraction especially expeller pressing, solvent extraction, and prepress-solvent extraction [3]. Nowadays, the use of organic solvents (usually hexane) raises health, safety, and environmental concerns due to their toxicity and their flammability. Various researches showed that hexane is a dangerous air pollutant and have hazardous repercussions on the human neuronal and respiratory system when inhaled [7,8]. In this same context, studies have shown the existence of a high toxicity in animals fed with the defatted meal containing residual hexane $[9,10]$. These complications lead to seeking safe alternatives to preserve environment and health. Among the solutions found so far, the integration of "green" solvents and the use of "green" extraction techniques such as Aqueous Enzymatic Extraction (AEE).

Aqueous Enzymatic Extraction (AEE) is an environmentally friendly extraction technique wherein water is used as an extraction medium instead of organic solvents. This technique relies on the application of enzymes to break down cell walls and promote the release of targeted intracellular components. Various types of enzymes are used in AEE like cellulase, pectinase, hemicellulase, $\alpha$-amylase, protease, and many others, depending on the structure of the seed $[11,12]$. Indeed, each enzyme is specific to a given substrate due to the complementarity between the shape of an enzyme's active site and the shape of its specific substrate [13]. AEE method has many advantages. It excludes or uses less organic solvents, provides oils that require less refining processes $[10,11]$ and ensures encouraging yields without compromising the oil quality. Several studies reported that hexane-extracted and aqueous enzymatic-extracted oils were very similar in terms of physicochemical characteristics and fatty acid profile [14-16].

AEE has been successfully applied for oil extraction from several oilseed species, such as sunflower (Pakistan), almond (Iran), olive (Tunisia), and peanut (India), using either individual or combination of enzymes [14,17-19]. To the best of our knowledge, only one study has investigated the AEE of safflower oil using cellulase and protease [20].

The application of enzymatic extraction in different processes depends on a proper understanding of the factors influencing extraction. Several factors affect the performance of AEE such as $\mathrm{pH}$, incubation time and temperature, agitation, type and concentration of enzyme, particle size of crushed seeds, and solid to liquid ratio [10]. Many authors have reviewed the main aspects relating to AEE [10-12].

The present study focused on evaluating the potential of AEE method, using hemicellulase enzyme, and determining extraction conditions that favor safflower oil recovery, which is a key step to optimize the overall process.

\section{Material and methods}

\subsection{Plant material and reagents}

The National Agricultural Research Institute (INRA, Regional Research Center, Meknes, Morocco) kindly provided safflower seeds of the Cartamar variety. The seeds were 
cleaned, finely ground in a laboratory grinder and stored at $-20{ }^{\circ} \mathrm{C}$ in the dark until further use.

The Hemicellulase enzyme from Aspergillus niger (H2125) was purchased from Sigma Aldrich. Its standard activity is 1.5 units/mg solid using a $\beta$-galactose dehydrogenase system and locust bean gum as substrate. It is reported having also cellulase activity $(0.03$ units/mg solid) as per the supplier's specifications. Hexane was of analytical grade and obtained from Sigma Aldrich.

\subsection{Solvent extraction of safflower seed oil}

Oil was chemically extracted from $25 \mathrm{~g}$ of safflower seed grinding powder in a soxhlet apparatus using $300 \mathrm{ml}$ of hexane at $60^{\circ} \mathrm{C}$ for 5 hours. Hexane was then eliminated under vacuum at $45^{\circ} \mathrm{C}$ using a rotary evaporator. The oil yield was calculated.

\subsection{Aqueous Enzymatic Extraction of safflower seed oil}

The procedure for Aqueous Enzymatic Extraction (AEE) is summarized in Figure1. Finely comminuted seeds $(3 \mathrm{~g}$ ) were added to $15 \mathrm{ml}$ of distilled water (ratio 1:5 w/v) in Erlenmeyer flasks. The $\mathrm{pH}$ was then adjusted with $0.1 \mathrm{~N} \mathrm{HCl}$ and $0.1 \mathrm{~N} \mathrm{NaOH}$ solutions. After adding the enzyme, the mixture was incubated in a water bath of adjustable temperature with constant shaking rate $(120 \mathrm{rpm})$.

After incubation, the Erlenmeyer flasks were placed directly in ice to stop the enzymatic reaction. Centrifugation (at $3500 \mathrm{rpm}$ for $20 \mathrm{~min}$ ) was then carried out to separate the oilyaqueous phase from the solid phase containing the seeds and the insoluble proteins. Only the oily-aqueous phase was collected in another tube and $5 \mathrm{ml}$ of hexane were added to facilitate the recovery of the oil contained in the emulsion. The hexane was then evaporated in a rotary evaporator at $45{ }^{\circ} \mathrm{C}$ and the oil recovery was calculated based on the yield obtained by the soxhlet extraction considered as control method.

$$
\text { oil recovery }(\%)=\frac{\text { oil yield extracted by AEE }}{\text { oil yield extracted by soxhlet }} * 100
$$

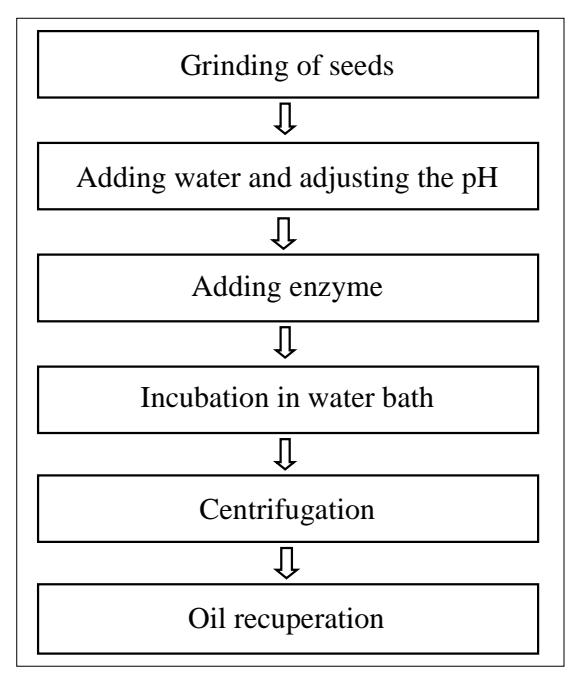

Fig.1. Schematic diagram of Aqueous Enzymatic Extraction of oil from safflower seeds 
The extraction conditions were evaluated in several single factor experiments to know the operational range of the most important and effective variables. The factors studied are: Incubation temperature with five levels $\left(40^{\circ} \mathrm{C}, 50^{\circ} \mathrm{C}, 60^{\circ} \mathrm{C}, 65^{\circ} \mathrm{C}\right.$ and $\left.70^{\circ} \mathrm{C}\right)$, initial $\mathrm{pH}$ with four levels (4.5, 5, 6 and 7), incubation time with five levels (1h, 2h, 3h, 6h and $8 \mathrm{~h})$ and enzyme concentration with eight levels $(0 \% \mathrm{w} / \mathrm{w}, 1 \% \mathrm{w} / \mathrm{w}, 2 \% \mathrm{w} / \mathrm{w}, 3 \% \mathrm{w} / \mathrm{w}, 4 \% \mathrm{w} / \mathrm{w}, 5 \%$ $\mathrm{w} / \mathrm{w}, 7.5 \% \mathrm{w} / \mathrm{w}$ and $10 \% \mathrm{w} / \mathrm{w})$.

\section{Results and discussion}

The conventional soxhlet method was used to determine the total amount of oil in safflower seeds. The oil extracted was $26.5 \pm 1.1 \%$ which is in agreement with the oil content reported in the literature for the Cartamar variety from Morocco [5].

In Aqueous Enzymatic Extraction, the choice of the enzyme is crucial and must be depending on the structure of the seed and its predominant components [21]. In the current study, AEE was performed using hemicellulase which is a group of enzymes that catalyzes the breakdown of heteropolysaccharides. It includes glucanases, xylanases and mannanases which act on glucan, xylan, and mannan respectively.

After incubation, separating oil from other slurry components was the major problem encountered during the process. When centrifugation was carried out, four phases appear according to their density (Fig. 2). At the bottom, the centrifugation pellet consists of insoluble protein precipitate and heavy seed particles, above which there is an aqueous phase containing soluble compounds like soluble proteins and sugars. Then, we find the emulsion phase and a few droplets of free oil, sometimes forming a thin film on the surface. Indeed, in Aqueous Enzymatic Extraction, destabilizing the emulsion still remains a serious challenge because a considerable proportion of the total oil remains stuck in the emulsion $[12,21]$. There are some methods mentioned in the literature for destabilizing the emulsion like phase inversion, freezing and thawing, shearing, microfiltration, $\mathrm{pH}$ adjustment, and phospholipase/protease treatments [22]. But they not allow recovering all the amount of the emulsified oil. In our study, we chose to add 3 to $5 \mathrm{ml}$ of hexane to recover all the oil entrapped in the emulsion and determine the total amount of oil obtained by AEE method.

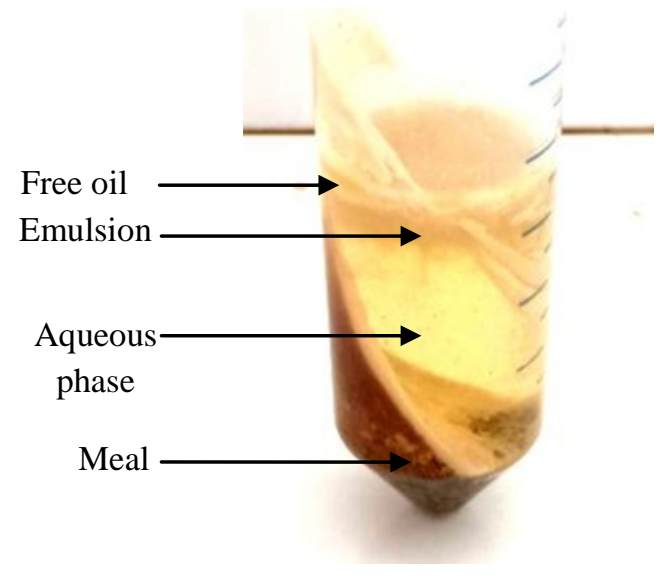

Fig.2. Different layers obtained following centrifugation after Aqueous Enzymatic Extraction of oil from safflower seeds 
In the current study, the effect of different factors on oil recovery was evaluated. Each factor was independently varied, keeping other parameters fixed, to obtain the best conditions for extracting oil from safflower seeds.

\subsection{Effect of temperature on safflower seed oil recovery}

Temperature is a critical factor in the extraction process because it directly affects the enzyme activity. The figure 3(A) shows the variation of safflower oil recovery in response to different incubation temperatures. As the temperature increases from 40 to $65^{\circ} \mathrm{C}$, so does the rate of oil recovery. The highest oil recovery is obtained at $65^{\circ} \mathrm{C}$ followed by a sharp decrease afterwards, due to the enzyme denaturation. Like all proteins, the thermal energy (high temperatures) disrupts the chemical bonds necessary to maintain the tertiary structure of the enzyme, which negatively affect the capacity of enzyme and substrate to fit together. On the other hand, at lower temperatures, enzyme and substrate have less kinetic energy and there are few interactions between them, which reduce or hinder the enzymatic activity. This characteristic pattern is reported in several works $[19,20]$.

Optimum temperature differs from one study to other depending on the thermo-stability of the enzyme, the plant species, and the other extraction conditions. In this study, $65^{\circ} \mathrm{C}$ is the recorded optimum temperature value for the enzyme activity. At this temperature, the enzyme seems to be more stable and gives the highest oil recovery $(70.45 \%)$. This result seems to be different from some studies which have shown that the optimum temperature for better enzyme activity is between 40 to $55{ }^{\circ} \mathrm{C}[19,20,23,24]$. However, it is in agreement with several other authors who find that the stability of the enzyme is enhanced with respect to extreme temperatures [25,26], and this enhance oil extraction. Nevertheless, a high temperature might affect the oil quality, particularly, the oxidation state. Consequently, analyzes of the oxidation stability of these oils extracted at high temperature must imperatively be carried out.

\subsection{Effect of pH on safflower seed oil recovery}

Another important parameter that influences the extraction of seed oil by AEE is the pH of the incubation medium. Indeed, Rovaris et al. [27] during a comparable study on soybean, showed that the oil yield obtained by AEE was higher when controlling $\mathrm{pH}$ compared to tests where the $\mathrm{pH}$ was uncontrolled. Thus, the effect of four different $\mathrm{pH}$ values of the AEE incubation medium on the oil recovery was tested. The result presented in figure 3(B) shows that the optimum $\mathrm{pH}$ for hemicellulase is $\mathrm{pH}=5$. Any incubation medium with a $\mathrm{pH}$ inferior or superior to this optimum value of 5 , results in a remarkable reduction in oil recovery. In fact, each enzyme has a specific optimal value depending on its type (acidic, neutral or alkaline enzyme). Under more acidic or more alkaline conditions, the enzyme denatures and no longer allows the substrate to bind to its site of action. In general, hemicellulase is an acidic enzyme and almost all studies employing hemicellulase use a $\mathrm{pH}$ range from 4 to 5 [28].

Several authors emphasized the importance of extracting oil in a $\mathrm{pH}$ different from the isoelectric point of substrate's proteins. Otherwise, substrate-enzyme interaction could be compromised due to the insolubility of the proteins [11,21]. In this study, the highest oil recovery was obtained at $\mathrm{pH} 5$ although it coincides with the isoelectric point of safflower proteins [29]. 


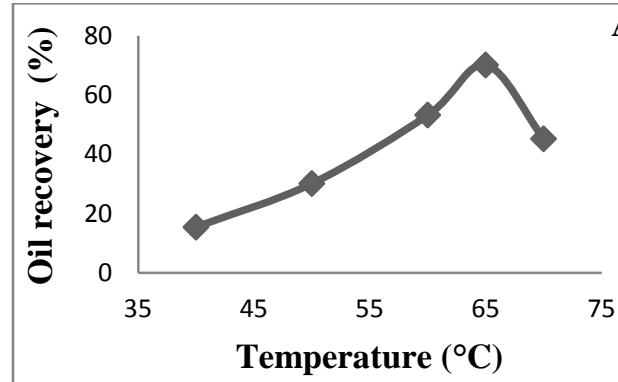

$\mathrm{pH} 4.5,1 \%$ enzyme, $4 \mathrm{~h}, 120 \mathrm{rpm}$

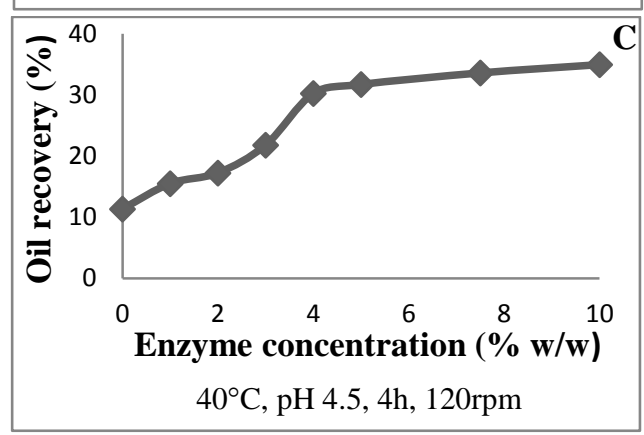

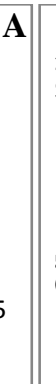

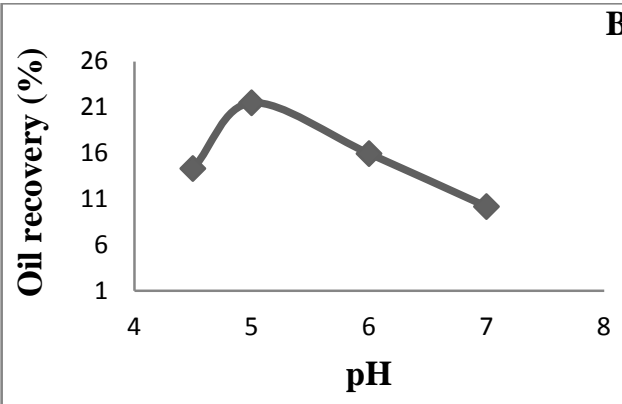

$40^{\circ} \mathrm{C}, 1 \%$ enzyme, $4 \mathrm{~h}, 120 \mathrm{rpm}$

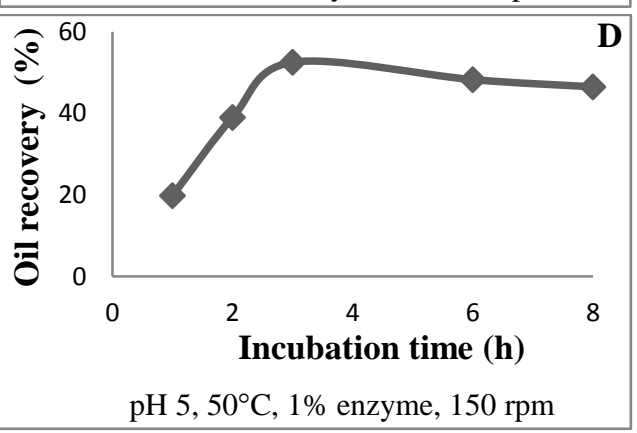

Fig.3. Effect of temperature (A), pH (B), enzyme concentration (C) and incubation time (D) on safflower seed oil recovery [3 g seeds, 1:5 solid: water ratio]

\subsection{Effect of enzyme concentration on safflower seed oil recovery}

The effect of enzyme concentration on oil recovery was investigated at eight different concentrations (Fig. 3(C)). The oil recovery initially increases with increasing enzyme concentrations, and then reaches a steady level with slight increase. An oil recovery of $11 \%$ is obtained for the control test (without addition of enzyme to the safflower seed oil extraction solution), while the addition of $10 \%$ enzyme (w/w) allows a clear improvement which corresponds to an oil recovery of $35 \%$. This result is in agreement with several previously published results which concluded that the use of enzymes improves the oil extraction process [15,17,30]. According to Mansouri et al. [3], safflower seeds of Cartamar variety used in this study, have cells with pectocellulosic walls that contain $21.22 \%$ hemicellulose, $31.35 \%$ cellulose and $17.4 \%$ lignin. Therefore, the use of hemicellulase enzyme (which has especially hemicellulase but also cellulase activity) allowed to destroy cell structural integrity and considerably facilitated the oil release comparably to the control.

The figure 3(C) shows that oil recovery hits a plateau at $4 \% \mathrm{w} / \mathrm{w}$ of hemicellulase, meaning that the gain in oil is no longer significant. That is, by exceeding $4 \%$ of enzyme concentration there is a very weak improvement, which does not economically justify the additional cost of the enzyme. Indeed, it has been reported that the high cost of enzymes is a serious challenge for the use of this extraction technique at the industrial level [10]. Hence, the interest in seeking a compromise between the enzyme quantity ensuring a high yield and its corresponding cost. Several studies have mentioned the importance of reaching the saturation phase of substrate active sites (by increasing enzyme concentration) in order to degrade the sample to the maximum and to promote oil recovery [20,31]. $4 \%$ is therefore suggested as the optimal hemicellulase concentration for safflower seed oil extraction. 
Nevertheless, an abuse in increasing enzymatic concentrations, in some cases, may hinder the oil extraction process and trigger off flavors, bitterness and caramelization of sugars [10].

\subsection{Effect of incubation time on safflower seed oil recovery}

Over the tested range of incubation time (1-8h), the oil recovery increases significantly during the first three hours (from $19.85 \%$ to $39 \%$ respectively at 1 and $3 \mathrm{~h}$ ), thereafter it decreases slightly (fig. 3(D)). In fact, the longer the incubation time increases, the greater the chances of promoting contact between the enzyme and the substrate. But, much longer extraction times do not necessarily result in higher yields, presumably due to the depletion of substrate. This pattern is supported by previously published studies on oil extraction from seeds of other safflower cultivars [20], from almond cake [32], Pinus pumila seeds [33] and rapeseeds [31].

The current study focused on the effect of four extraction factors mainly incubation temperature, $\mathrm{pH}$, enzyme concentration, and incubation time. Nevertheless, other influential parameters relating to the process should not be neglected such as particle size of crushed seeds, agitation, and solid to liquid ratio. Generally, small particle size promote higher yield due to easier access of enzymes to their action sites [20]. The stirring rate helps mechanically disrupt the cell membranes and homogenize the components of the reaction mixture. Solid-liquid ratio is also a factor to consider. Low humidity can cause a thick suspension that hinders enzyme activity. However, high water amount leads to enzyme dilution and an oil yield decrease [10,11].

Overall, the optimum conditions for the aqueous enzymatic extraction of safflower oil using hemicellulase were $65^{\circ} \mathrm{C}, \mathrm{pH} 5,4 \% \mathrm{w} / \mathrm{w}$ of enzyme and 3 hours of incubation. It is worth mentioning that the combination of these optimal values gave a yield of $12 \%$ corresponding to $45 \%$ of oil recovery only. However, among the experimental tests carried out, a maximum oil recovery of $70.45 \%$ was obtained for a $\mathrm{pH} 4.5,1 \%$ hemicellulase, $4 \mathrm{~h}$, and $65^{\circ} \mathrm{C}$. This result implies that there is a strong interaction between the factors which is also in accordance with previous reports in the literature [14,30,34]. This finding clearly highlights the need for a statistical design of experiments to take into account the effect of the interaction.

In an earlier study, Gibbins [20] has also investigated the AEE of safflower oil from Dincer variety and found that the optimum conditions using the enzyme Celluclast $1.5 \mathrm{~L}$ (a cellulase) were $\mathrm{pH} 4.84,48.3^{\circ} \mathrm{C}, 0.25 \mathrm{~mL}$ enzyme/g substance, particles of $<0.6 \mathrm{~mm}$, giving a maximum oil recovery of $65 \%$ which is slightly lower than our result. The current study proves that AEE has a great potential in extracting oil from safflower seeds since high oil recovery has been achieved $(70.45 \%)$ using a single enzyme. The combination of several enzymes like cellulase and protease could further significantly increase the oil yield [33]. Indeed, enzyme mixtures promote extraction because each one targets a welldetermined site and cooperates together facilitating the oil release $[13,14,33]$. In general, combining at least one cellulase, hemicellulase, pectinase, and protease is more effective for maximum oil recovery. Cellulase, hemicellulase and pectinase act on cell walls by degrading them and facilitating the action of the protease which will degrade the proteins that bind to oil bodies.

According to the literature, the maximum oil recovery reached in this study was better than that obtained from sesame (57.4\%) [16], soybean (29.48\%) [27] and bayberry kernels $(49.44 \%)[34]$. Other studies have even been able to achieve an oil recovery greater than $90 \%$ in peanut [19], palm fruit [30], watermelon kernels [24] and corn germ [15] by combining several enzymes and optimizing the process. 


\section{Conclusion}

Safflower oil was extracted by AEE method from Cartamar variety employing hemicellulase enzyme. The results obtained show that processing variables (duration and temperature of incubation, $\mathrm{pH}$, enzyme concentration) have remarkable effects on the oil recovery. The applicability of the process was demonstrated since a maximum of $70.45 \%$ recovery was achieved. Aqueous Enzymatic Extraction (AEE) is therefore suggested as a promising green chemistry technique.

An optimization of safflower oil extraction by Response Surface Methodology (RSM) is envisaged. The present preliminary study, elucidating individual effects of extraction parameters, will therefore be of great interest in choosing the effective ranges for each independent variable in RSM.

\section{References}

1. S. Krist, in Veg. Fats Oils, 657-664 (2020)

2. B. Aydeniz, O. Güneşer, and E. Yılmaz, J. Am. Oil Chem. Soc. 91, 99-101 (2014)

3. F. Mansouri, A. Ben Moumen, G. Richard, M. L. Fauconnier, M. Sindic, A. Elamrani, and H. Serghini Caid, OCL - Oilseeds Fats, Crop. Lipids 25, 1-9 (2018)

4. J. Yeo, S. Fereidoon, and J. Smith, in Bailey's Ind. Oil Fat Prod, edited by F. Shahidi, 7th ed. 533-576 (John Wiley \& Sons, Ltd, 2020)

5. A. Ben Moumen, F. Mansouri, G. Richard, M. Abid, M. L. Fauconnier, M. Sindic, A. Elamrani, and H. Serghini Caid, Int. J. Food Sci. Technol. 50, 804-810 (2015)

6. N. Khalid, R. S. Khan, M. I. Hussain, M. Farooq, A. Ahmad, and I. Ahmed, Trends Food Sci. Technol. 66, 176-186 (2017)

7. A. Herskowitz, N. Ishii, and H. Schaumburg, N. Engl. J. Med. 285, 82-85 (1971)

8. A. I. Rascu, Rom. J. Leg. Med. 23, 279-284 (2015)

9. U.S. Environmental Protection Agency, TOXICOLOGICAL REVIEW OF NHEXANE: In Support of Summary Information on the Integrated Risk Information System (IRIS) (Washington, DC, 2005)

10. S. P. J. Kumar, S. R. Prasad, R. Banerjee, D. K. Agarwal, K. S. Kulkarni, and K. V. Ramesh, Chem. Cent. J. 11, 1-7 (2017)

11. P. W. Mwaurah, S. Kumar, N. Kumar, A. K. Attkan, A. Panghal, V. K. Singh, and M. K. Garg, Compr. Rev. Food Sci. Food Saf. 19, 3-20 (2020)

12. J. J. Liu, M. A. A. Gasmalla, P. Li, and R. Yang, Innov. Food Sci. Emerg. Technol. 35, 184-193 (2016)

13. G. Ricochon and L. Muniglia, OCL - Ol. Corps Gras Lipides 17, 356-359 (2010)

14. M. Balvardi, K. Rezaei, J. A. Mendiola, and E. Ibáñez, JAOCS, J. Am. Oil Chem. Soc. 92, 985-992 (2015)

15. R. A. Moreau, D. B. Johnston, M. J. Powell, and K. B. Hicks, J. Am. Oil Chem. Soc. 81, 1071-1075 (2004)

16. S. Latif and F. Anwar, Food Chem. 125, 679-684 (2011)

17. S. Latif and F. Anwar, JAOCS, J. Am. Oil Chem. Soc. 86, 393-400 (2009)

18. N. Hadj-Taieb, N. Grati, M. Ayadi, I. Attia, H. Bensalem, and A. Gargouri, Biochem. Eng. J. 62, 79-85 (2012)

19. A. Sharma, S. K. Khare, and M. N. Gupta, JAOCS, J. Am. Oil Chem. Soc. 79, 215218 (2002)

20. R. D. Gibbins, H. A. Aksoy, and G. Ustun, Int. J. Food Sci. Technol. 47, 1055-1062 (2012)

21. M. Mat Yusoff, M. H. Gordon, O. Ezeh, and K. Niranjan, Food Chem. 211, 400408 (2016) 
22. S. Jung, D. Maurer, and L. A. Johnson, Bioresour. Technol. 100, 5340-5347 (2009)

23. J. Long, Y. Fu, Y. Zu, J. Li, W. Wang, C. Gu, and M. Luo, Bioresour. Technol. 102, 9991-9996 (2011)

24. X. Sui, L. Jiang, Y. Li, and S. Liu, Procedia Eng. 15, 4673-4680 (2011)

25. L. Wang, F. Liu, T. Li, D. Liu, Y. Xu, and Y. Yang, Appl. Sci. 8, 1-14 (2018)

26. P. Maijala, N. Kango, N. Szijarto, and L. Viikari, Antonie Van Leeuwenhoek 101, 905-917 (2012)

27. Â. A. Rovaris, C. O. Dias, I. P. da Cunha, R. M. C. Scaff, A. de Francisco, C. L. O. Petkowicz, and E. R. Amante, Ind. Crops Prod. 36, 405-414 (2012)

28. K. Boutemak, N. Benali, and N. Moulai-Mostefa, Int. J. Chem. Mol. Eng. 9, 1508$1511(2015)$

29. J. A. Ulloa, P. Rosas-Ulloa, and B. E. Ulloa-Rangel, J. Sci. Food Agric. 91, 572577 (2011)

30. C. B. Teixeira, G. A. Macedo, J. A. Macedo, L. Helena, M. Silva, A. Manoel, and C. Rodrigues, Bioresour. Technol. 129, 575-581 (2013)

31. B. S. Zhang, Z. Wang, and S. Y. Xu, J. Am. Oil Chem. Soc. 84, 97-105 (2007)

32. T. S. P. Souza, F. F. G. Dias, M. G. B. Koblitz, and J. M. L. N. Juliana, Processes 7, 1-19 (2019)

33. F. Chen, Q. Zhang, H. Gu, and L. Yang, J. Chromatogr. A 1471, 68-79 (2016)

34. Y. L. Zhang, S. Li, C. P. Yin, D. H. Jiang, F. F. Yan, and T. Xu, Food Chem. 135, 304-308 (2012) 